\title{
Soviets seek Japan's help over Chernobyl accident
}

\section{- Soviet team visits atomic war site - Hiroshima researchers devise programme}

\section{London}

THE Soviet Union is planning a major survey of the medical consequences of the Chernobyl disaster based on a health monitoring programme drawn up by the Radiation Effects Research Foundation at Hiroshima, Japan. A Soviet team of five, which has just spent 10 days in Japan at the request of the Soviet side, was presented with the monitoring programme at the end of its stay.

The object of the monitoring programme will be to monitor, and attempt the prognosis and treatment of, the longterm effects on those exposed to radiation around and near Chernobyl. As part of the programme, an attempt will be made to determine the doses of radiation to which people were exposed.

The last question is important. Except for the inhabitants of the town of Pripyat, who were evacuated the day after the accident on 27 April last year, other people in the $30-\mathrm{km}$ zone around Chernobyl were not moved until several days after the accident, although radioactivity continued to escape from the damaged reactor until 8 May.

Soviet medical scientists at the postaccident review conference at Vienna in August, 1986, spoke in terms of an eventual few thousand extra deaths from cancer among the 135,000 persons from the $30-\mathrm{km}$ zone, but estimates of this order seemed to be little better than 'best guesses'. Soviet participants at Vienna indicated that, then, they were by no means certain of the levels of contamination of individuals either within the $30-\mathrm{km}$ zone or beyond.

At the same meeting, the Soviet delegation indicated that the best memorial to those who had died and those who were yet to die as a result of the Chernobyl accident would be to wring all possible information from the disaster. The question of whether or not there is a minimum exposure below which radiation produces no harmful effects was singled out for attention.

The logistics of such a follow-up programme are formidable. Not only will it entail the lifelong monitoring of the inhabitants of the $30-\mathrm{km}$ zone, but it will also require the selection of an appropriate control population.

The latter will undoubtedly find regular check-ups increasingly tedious as the years pass, but there may be some difficulty in matching the control subjects for comparable lifestyle while, at the same time, going sufficiently far from Chernobyl to ensure that contamination of the control subjects is no more than background contamination.

Nevertheless, the Soviet team declared in Vienna that a survey would be carried out once plans had been drawn up; a training programme for medical personnel was to have been launched immediately. The visit to Hiroshima, and the handing of the Japanese monitoring programme, suggest that the follow-up programme is well on the way to becoming a reality. The Soviet physicians told their Japanese hosts that the results of the study would be "announced internationally" for the benefit of world medicine.

Japan is undoubtedly best fitted by history to provide the details of a monitoring programme, although there is one respect in which Japanese experience and that of the Soviet monitoring teams are not entirely comparable. The survivors of Hiroshima and Nagasaki had not been exposed to contamination by heavy radionuclides, whereas much of the longterm radiation exposure consequent on Chernobyl is likely to be caused by inhaled or ingested radioactivity.

A particular consequence of the accident now being brought to light is the possibility that 'micro-hotspots' consisting of small particles of radioactivity may have been more widely distributed after Chernobyl than first seemed possible. Although the amount of the fuel which 'relocated' in areas remote from the reactor site was only a minute fraction of the whole, 'micro-hotspots' were recorded as far afield as Sweden in the first reports of radioactivity after the accident.

Although the early Soviet medical work after Chernobyl concentrated on radioiodine and caesium, recent Soviet reports obliquely indicate that hotspot contamination is causing increasing concern. No details of heavy nuclide contamination within the Soviet Union is available so far (apart from anecdotal evidence from the clothes and baggage of returning tourists, see Nature 323, 399; 1986), but a Polish nuclear safety expert, who preferred not to be identified, said in October that whole-body monitoring suggests that as many as one in ten inhabitants of Warsaw has ruthenium hotspots in his or her lungs, while in Bialystok, close to the frontier of the Byelorussian SSR, the proportion may be as high as one in three.
British nuclear industry in trouble again

\section{London}

BRITAIN's nuclear lobby is under fire in the wake of the disclosure that the Sellafield reprocessing plant in Cumbria is to be closed down for two weeks because of a leak and reports that the United Kingdom's advanced gas-cooled reactors (AGR) have a design fault.

These incidents are likely to revive the opposition to the building of the $£ 1,300$ million pressurized water reactor (PWR) at Sizewell on the Suffolk coast, despite tacit approval for its construction by a report published last week. The (see Nature 325, 377 and 378; 1987) study by Sir Frank Layfield has been criticized by, among others, two major environmental lobbyists, the Friends of the Earth and the Council for the Protection of Rural England, which say the study avoids issues and is irrelevant after Chernobyl.

The council was scathing. It claimed that "since the inquiry closed, events have moved on radically. Not only have the allimportant cost of other fuels - coal and oil - fallen through the floor, but also the Central Electricity Generating Board's (CEGB, operators of the plant) own estimate of what Sizewell B will cost to build has soared, by more than 11 per cent ( $£ 127$ million), before even a brick has been laid."

But the leaks at Sellafield and the alleged AGR design fault will do more damage than any protest from ecologists to the nuclear case. Sellafield management was warned by the Nuclear Installations Inspectorate (NII) the safety watchdog of the nuclear industry and the body responsible for implementing the conditions of the nuclear operating licences, that the plant would be closed within a year if safety recommendations were not carried out.

The latest leak is the third in the past three weeks and will mean the complex will have to close for up to two weeks. The AGR design faults, believed to be a weakness in the control rods, will also apply to the two reactors being built at Heysham, near Blackpool and Torness, Scotland, at a cost of $£ 1,000$ million each.

These disclosures will undermine the credibility of the Layfield study. While the PWR design is significantly different from that of AGR, the Layfield survey emphasizes that not all the safety aspects of the PWR design have been tested, nor could they be at this stage. The long-term safety of the nuclear design depends on assurances given by CEGB and NII, an admission that shocked many opponents of CEGB and NII. 